\title{
ANTINUCLEAR ANTIBODIES IN PATIENTS WITH UNEXPLAINED RECURRENT ABORTIONS
}

\author{
ANUPRIYA ASAITHAMBI ${ }^{*}$, MANJULA GUNASEKARAN ${ }^{2}$, MANIVELAN S $^{3}$, PALANIAPPAN NAINAR ${ }^{4}$
}

${ }^{1}$ Department of Microbiology, Chennai Medical College Hospital and Research Centre, Irungalur, Trichy - 620 105, Tamil Nadu, India. ${ }^{2}$ Department of Microbiology, Madurai Medical College, Madurai, Tamil Nadu, India. ${ }^{3}$ Department of Microbiology, Chennai Medical College Hospital and Research Centre, Irungalur, Trichy - 620 105, Tamil Nadu, India. ${ }^{4}$ Department of Microbiology, Sree Mookambika Institute of Medical Sciences, Kulasekharam, Tamil Nadu, India. Email: dranupriya03@yahoo.co.in

Received: 07 April 2017, Revised and Accepted: 10 May 2017

\section{ABSTRACT}

Objective:This study aims to determine the prevalence of antinuclear antibodies in pregnant women with bad obstetric history (BOH) against healthy multigravid women in and around Tirunelveli district

Methods: This is a case-control study comprising 60 antenatal women with BOH against 60 multiparous pregnant women with no history of abortions. Antinuclear antibodies (ANA) were detected using indirect immunofluorescence with Hep-2 cell substrate, and enzyme-linked immunosorbent assay (ELISA).

Results: Among BOH cases 19 (82.6\%), 18 (78.26\%) were positive by ELISA and indirect fluorescence antibody test (IFAT) method, respectively. Among controls, $4(17.39 \%)$ and $5(21.73 \%)$ individuals were positive by ELISA and IFAT methods, respectively. Of the 18 positives, homogenous pattern was most common followed by anticentromere pattern, fine speckled and coarse speckled pattern

Conclusion: IFAT is considered to be gold standard in the diagnosis of autoimmune disorders, but ELISA appears to be a suitable simple alternative for testing rheumatological disorders.

Keywords: Antinuclear antibodies, Bad obstetric history, Indirect immunofluorescence.

(C) 2017 The Authors. Published by Innovare Academic Sciences Pvt Ltd. This is an open access article under the CC BY license (http://creativecommons. org/licenses/by/4. 0/) DOI: http://dx.doi.org/10.22159/ajpcr.2017.v10i8.18343

\section{INTRODUCTION}

Autoimmune disorders are 6-10 times more common among women than men [1], and they are likely to have their onset during the reproductive years. Screening of patients for subclinical autoimmune disease has been a matter of controversy for years. The causes of recurrent fetal wastage are multifactorial, and sometimes more than one factor may be present in a case, which could be recurrent or nonrecurrent. Pregnancy is faced with a number of self and foreign antigens that modulate the immune system of the mother. If immune response of mother is altered, frequent abortions may result.

Presence of autoantibodies causes rejection of early pregnancy in 30\% of women [2,3]. Antibodies responsible are antinuclear antibodies and antiphospholipid antibodies: Lupus anticoagulant, and anticardiolipin antibodies. Antinuclear antibodies may interfere with the formation and maturation of placenta which would eventually lead to an early fetal loss. Histone proteins and deoxyribonucleic acid induce tissue development. Formation of antibodies against these histone proteins may lead to activation of the autoimmune process in mother and thereby end up in abortion.

There are various techniques for antinuclear antibodies (ANA) detection. Indirect immunofluorescence continues to be a basic technique in autoimmunity studies. Autoantibodies give characteristic fluorescence images called fluorescent patterns. It is inexpensive and easy to perform with a high degree of sensitivity and specificity and is considered to be gold standard, but some results may be misinterpreted. As it detects several different antibodies, cross-reactions can occur. Immunofluorescence can give false positive result in up to $3 \%$ of the population [4].

Enzyme-linked immunosorbent assay (ELISA) can also be used for diagnosis of autoantibodies, there are two types of ELISA methods employed for ANA testing. The generic assay is the one which detects ANA of broad specificity and the other is called specific antigen assay that detects a particular autoantibody as it reacts with single autoantigen. ELISA is highly specific and sensitive and decreases the time involved in screening a large number of patient samples. ELISA is simple to perform, can be automated and it does not require person with high technical skill who could recognize microscopic patterns.

\section{MATERIALS AND METHODS}

\section{Setting of the study}

This study was conducted from the period of November 2011 to June 2012. The study population comprises mainly of pregnant women from 19 to 40 years, attending antenatal clinic and inpatients in Obstetrics and Gynecology Department, Tirunelveli Medical College Hospital. This is a case-control study comprising an equal number of cases and controls, each comprising 60 women of reproductive age group.

\section{Study population}

The study population comprises 60 pregnant women from age group 19 to 40 years.

- With a history of two or more spontaneous abortions.

- It also includes women with past history of stillbirths, intrauterine death, or early neonatal deaths.

The population was carefully selected that women in study group have no live issues. The control group comprises 60 multiparous pregnant women from age group 19 to 40 years, with no history of abortions.

\section{Exclusion criteria}

It includes women with history of heart disease, anemia, renal failure, $\mathrm{Rh}$ incompatibility, history of sexually transmitted diseases, or TORCH infections, uterine fibroids, endometriosis, pelvic inflammatory 
disease, uterine anomalies and septate uterus, and bicornuate uterus. Institutional ethical clearance was obtained.

Informed written consent was obtained from all pregnant women involved in the study. Details of history and physical examination findings were noted. In all patients hemoglobin, blood group, fasting blood sugar, ultrasonography, and TORCH test were done by standard methods.

\section{Methodology}

Under strict aseptic precautions, $3-5 \mathrm{ml}$ blood was collected from both study group and control group and subjected to indirect immunofluorescence using Hep-2 cells (BioSystems Pvt. Ltd.)). Serum ANA bind to the corresponding antigens present in Hep- 2 cells. The resulting antigen-antibody complexes are detected by means of a fluorescein-labeled anti-human immunoglobulin (IgG) and visualized with the aid of a fluorescence microscope.

The serum samples were also subjected to ELISA. Specific ANA in the sample bind to the antigens immobilized on the microwell surface. In a second incubation, a conjugate of horseradish peroxidaselabeled IgG's to human IgG binds to surface-bound antibodies. Finally, 3,3',5,5'-tetramethylbenzidine with hydrogen peroxidase was added to each well as enzyme substrate and, after color development, the enzymatic reaction was stopped with hydrochloric acid. The yellow product formed was measured in terms of absorbance units at $450 \mathrm{~nm}$, and its proportional to the amount of antibodies present.

\section{Statistics}

Data regarding the cases and controls were described in terms of percentages. Sensitivity, specificity, positive predictive value (PPV), and negative predictive value (NPV) of ELISA were done. The cases and controls were statistically analyzed for significance by Chi-squared test. The Chi-squared test was calculated for the analytic assessment by SPSS 20 version software. The differences were considered to be statistically significant when the $\mathrm{p}<0.05$.

\section{RESULTS}

Table 1 shows age-wise distribution of bad obstetric history (BOH) cases and antinuclear antibodies positive among them. Of the 7 samples tested from age group 16 to 20 years, 1 sample is positive and remaining were negative. Of the 13 cases tested 3 were positive, and 10 were negative in the age group 21-25 years. From 26 to 30 years, 21 samples were tested, of which 8 samples were positive, and remaining 13 were tested negative. 12 individuals were tested from age group 31 to 35 years, 6 were positive and remaining 6 were negative. Among 7 cases tested from age group 36 to 40 years, none were positive. The mean age among cases is 28 years.

Table 2 shows the distribution of ANA positivity among cases and controls. Among 60 women with BOH, 18 (30\%) were found to be positive. Among controls 5 (8.3\%) women were positive.

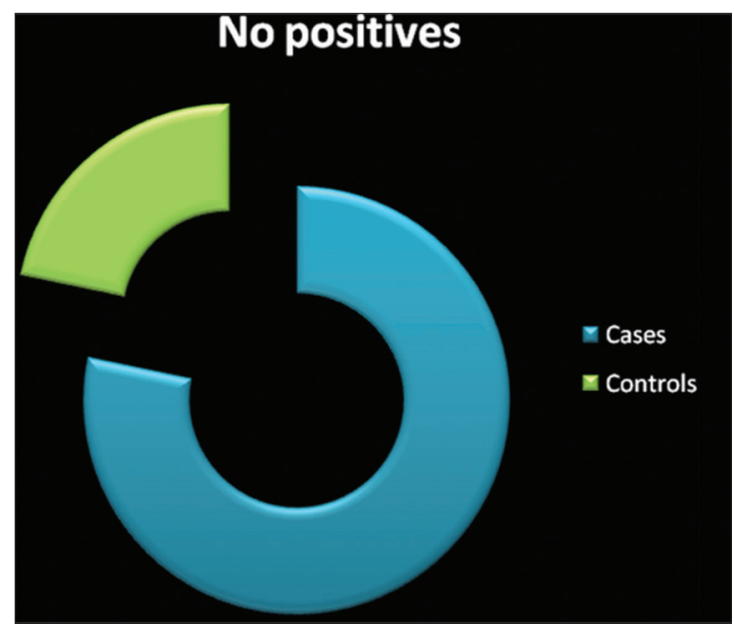

Among 60 cases with BOH, $18(30 \%)$ tested positive for ANA by immunofluorescence and $42(70 \%)$ were ANA negative. Of the total 60 multigravid women, $5(8.3 \%)$ of them tested positive for ANA by indirect fluorescence antibody test (IFAT), and the remaining $55(91.66 \%)$ were negative. The association between women with BOH and multigravid controls, using immunofluorescence was considered to be statistically significant (Table 3 ).

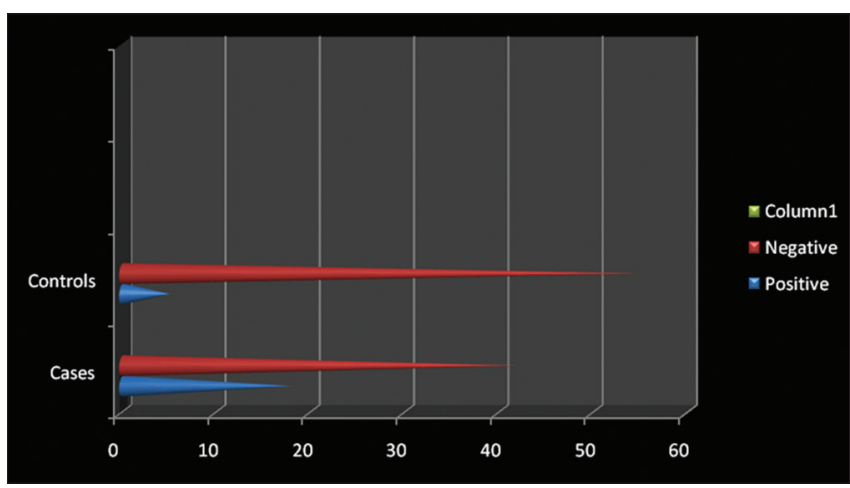

Table 4 shows the distribution of HEp- 2 cell pattern among the 23 IFAT positives which include both cases and controls. Of the 18 positives, homogenous pattern was seen in $8(44.44 \%)$, anticentromere pattern in $6(26.08 \%)$, fine speckled in $4(17.39 \%)$, coarse speckled pattern in $3(13.04 \%)$, vimentin and nuclear rim pattern were seen in $2(8.69 \%)$ patients.

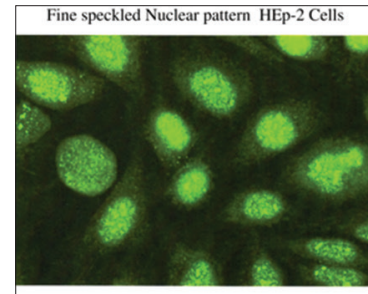

Centromere Pattern, HEp2 Cells
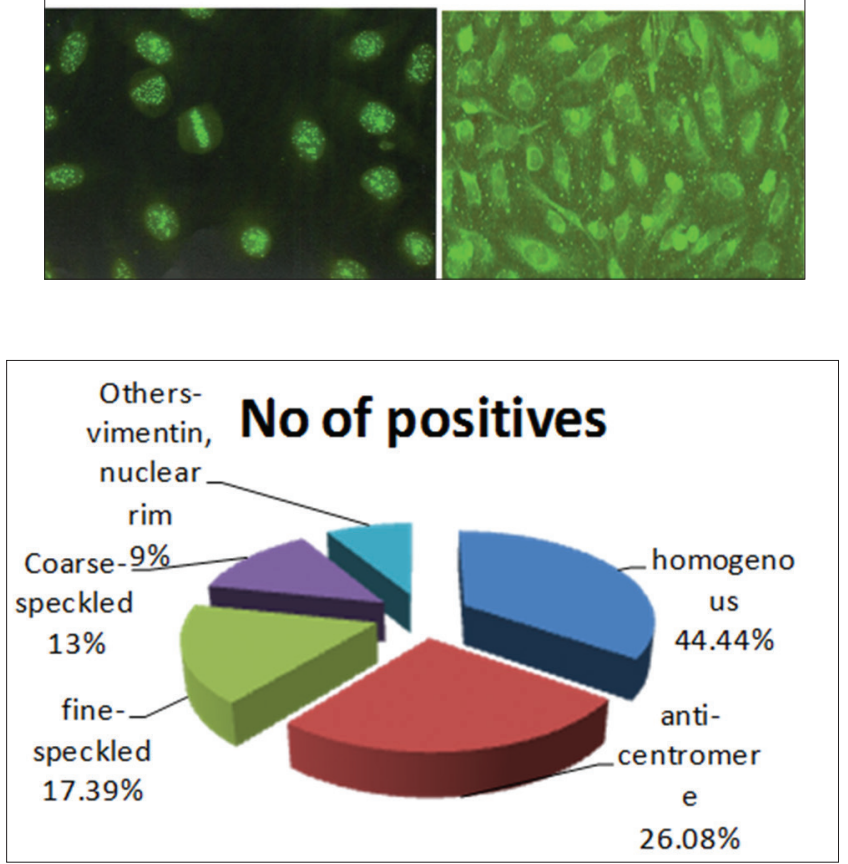

Among 60 cases with BOH, 19 (31.6\%) tested positive for ANA by ELISA and $41(68.33 \%)$ were ANA negative. Of the total 60 multigravid women, $4(6 \%)$ of them tested positive for ANA by ELISA, and the remaining 
Table 1: Age-wise distribution of $\mathrm{BOH}$ women with ANA positivity

\begin{tabular}{|c|c|c|c|c|}
\hline \multirow[t]{2}{*}{ S. No. } & \multirow{2}{*}{$\begin{array}{l}\text { Age in } \\
\text { years }\end{array}$} & \multirow{2}{*}{$\begin{array}{l}\text { No of samples } \\
\text { tested }\end{array}$} & \multicolumn{2}{|l|}{ n (\%) } \\
\hline & & & $\begin{array}{l}\text { ANA positive } \\
\text { cases }\end{array}$ & $\begin{array}{l}\text { ANA negative } \\
\text { cases }\end{array}$ \\
\hline 1 & $16-20$ & 7 & $1(5.55)$ & $6(14.28)$ \\
\hline 2 & $21-25$ & 13 & $3(16.66)$ & $10(23.80)$ \\
\hline 3 & $26-30$ & 21 & $8(44.44)$ & $13(30.95)$ \\
\hline 4 & $31-35$ & 12 & $6(33.55)$ & $6(14.28)$ \\
\hline \multirow[t]{2}{*}{5} & $36-40$ & 7 & - & 7 (16.69) \\
\hline & Total & 60 & $18(100)$ & $42(100)$ \\
\hline
\end{tabular}

ANA: Antinuclear antibodies, BOH: Bad obstetric history

Table 2: ANA positivity among cases and controls

\begin{tabular}{lll}
\hline Samples & Total number & ANA positivity \\
\cline { 3 - 3 } & & $\mathbf{n}(\%)$ \\
\hline Cases & 60 & $18(30)$ \\
Controls & 60 & $5(8.3)$ \\
\hline
\end{tabular}

Table 3: Evaluation of ANA among cases and controls using immunofluorescence

\begin{tabular}{lll}
\hline Samples & $\mathbf{n}(\%)$ & \\
\cline { 2 - 3 } & IFAT (+) & IFAT (-) \\
\hline Cases $(\mathrm{n}=60)$ & $18(30)$ & $42(70)$ \\
Controls $(\mathrm{n}=60)$ & $5(8.3)$ & $55(91.66)$ \\
Total & $23(38.3)$ & 97 \\
\hline
\end{tabular}

$\mathrm{p}<0.001$ (statistically significant). IFAT: Indirect fluorescence antibody test

Table 4: Distribution of HEp-2 cell pattern among IFAT positives

\begin{tabular}{ll}
\hline HEp-2 cell pattern & Number of positives (\%) \\
\hline Homogenous & $8(44.44)$ \\
Anticentromere & $6(26.08)$ \\
Fine speckled & $4(17.39)$ \\
Coarse speckled & $3(13.04)$ \\
Others vimentin, nuclear rim & $2(8.69)$ \\
\hline IFAT: Indirect fluorescence antibody test &
\end{tabular}

56 (93.33\%) were negative. The association between ANA positivity, for women with $\mathrm{BOH}$ and controls were considered to be statistically significant (Table 5).

Table 6 compares ANA positivity among cases and controls by both ELISA and IFAT method. Among BOH cases 19 (82.6\%), 18 (78.26\%) were positive by ELISA and IFAT method, respectively. Among controls, $4(17.39 \%)$ and $5(21.73 \%)$ individuals were positive by ELISA and IFAT methods, respectively.

ELISA reported one more women with $\mathrm{BOH}$ as ANA positive, which IFAT failed to detect. Among controls, ELISA missed one sample as ANA positive while IFAT reported as positive.

ELISA test was evaluated for its sensitivity and specificity against IFAT, gold standard test. Table 7 shows sensitivity, specificity, PPV, and NPV of ELISA are $94.7 \%, 95.12 \%, 90 \%$, and $97.5 \%$, respectively.

\section{DISCUSSION}

In this study, the mean age among cases and controls is around 28 years. Patton [5] tested sera from 136 women (84 pregnant and 52 nonpregnant) for antibodies directed against nuclear antigens, the mean ages of the two groups were 32 and 26 years, respectively.
Table 5: Evaluation of seropositivity among BOH cases and controls using ELISA

\begin{tabular}{lll}
\hline Samples & Cases (\%) & \\
\cline { 2 - 3 } & ELISA (+) & ELISA (-) \\
\hline Cases $(\mathrm{n}=60)$ & $19(31.6)$ & $41(68.33)$ \\
Controls $(\mathrm{n}=60)$ & $4(6)$ & $56(93.33)$ \\
Total & 23 & 97 \\
\hline
\end{tabular}

$\mathrm{p}<0.001$ (statistically significant). ELISA: Enzyme-linked immunosorbent assay, BOH: Bad obstetric history

Table 6: Comparison of ELISA and IFAT for ANA positivity among cases and controls

\begin{tabular}{llc}
\hline Study population & \multicolumn{2}{l}{ Number of positives (\%) } \\
\cline { 2 - 3 } & ELISA & IFAT \\
\hline Cases $(\mathrm{n}=60)$ & $19(82.6)$ & $18(78.26)$ \\
Controls $(\mathrm{n}=60)$ & $4(17.39)$ & $5(21.73)$ \\
\hline p<0.05 not significant. ELISA: Enzyme-linked immunosorbent assay, \\
IFAT: Indirect fluorescence antibody test, and ANA: Antinuclear antibodies
\end{tabular}

Table 7: Evaluation of ELISA for detecting ANA positivity among cases with $\mathrm{BOH}$

\begin{tabular}{llll}
\hline \multirow{2}{*}{ ELISA } & \multicolumn{2}{l}{ IFAT } & \multirow{2}{*}{ Total } \\
\cline { 2 - 3 } & Positive & Negative & \\
\hline Positive & 18 & 2 & 20 \\
Negative & 1 & 39 & 40 \\
Total & 19 & 41 & \\
\hline
\end{tabular}

ELISA: Enzyme-linked immunosorbent assay, ANA: Antinuclear antibodies

A study from Sweden also reported the similar findings were the risk of abortions is $8.7 \%$ at age 24 and rises up to $24.7 \%$ at the age of 35 .

In this study, antinuclear antibodies were found in 18 (30\%) women with RPL and $5(8.3 \%)$ in the control group, which is comparable to the study conducted by Garcia et al. [6] and Nakatsuka et al. [7] where the prevalence of ANA among women with $\mathrm{BOH}$ was $30 \%$ and $43.5 \%$ when compared to women in control groups which were about $6.6 \%$ and $22.4 \%$, respectively.

The occurrence of ANA in normal pregnancy has been variably reported to range from 1 to $53 \%$. In this study $5(8.3 \%)$ women were found to be positive for ANA which is in accordance with the study conducted by Farnam et al. [8] where he reported ANA in about $10.7 \%$ pregnant women in low titers. This indicates that ANA can be found in normal pregnancy due to some infectious etiology and not only because of collagenosis.

In this study, 23 women were positive for antinuclear antibodies including $18(30 \%)$ of women with $\mathrm{BOH}$ and $5(8.3 \%)$ controls by indirect immunofluorescence using HEp-2 cell as substrate. Similar findings are reported by Garcia et al. [6], Xu et al. [9].

Among the nuclear patterns, the most frequent consist of homogeneous/ peripheral fluorescence (DNA, deoxyribonucleoprotein, and histones) and speckled fluorescence (RNP, Sm, Ro/SSA, and La/SSB); the relatively less frequent patterns include the centromeric (CENP-A, CENP-B, and CENP-C), and cytoplasmic patterns. Our study revealed homogenous pattern in 8 (44.44\%), followed by speckled pattern in 7 (38.85\%), and anticentromere pattern in $6(26.08 \%)$. Cytoplasmic pattern was seen only in $1(4.65 \%)$ individual. The nuclear patterns were comparable with the findings of Satoh et al. [10] in the USA, and Afman [11] in South Africa. 
In our study among 120 patients tested for ANA, 19 (31.8\%) of women with $\mathrm{BOH}$ and $4(6 \%)$ of controls were reported to be positive by ELISA. A study from Saudi Arabia [12], has the similar findings.

In this study, antinuclear antibodies were positive in 18 (30\%) cases by IFAT and 19 (31.6\%) cases by ELISA. Among the control, population tested for antinuclear antibodies 5 (8.3\%), and 4 (6\%) samples were reported to be positive by IFAT and ELISA, respectively. The sensitivity, specificity, PPV, and NPV of ELISA for antinuclear antibodies were found to be $94.7 \%, 95.12 \%, 90 \%$, and $97.5 \%$, respectively.

A study conducted in Japan by Kumagai and Hayashi [13] screened 257 healthy subjects between COBAS-ANA and IF-ANA. The sensitivity and specificity of COBAS-ANA were $84 \%$ and $94 \%$, respectively. Divate et al. [14], investigated the sera from 96 patients and found the sensitivity, specificity, PPV, and NPV of ELISA were 90.7\%, 85.7\%, $89.1 \%$, and $87.8 \%$, respectively.

IFAT is considered as gold standard method for ANA detection, but this technique has some drawbacks. There are chances for false positive results in up to $3 \%$ of normal population. ANA levels tend to rise and fall, and sometimes being undetectable when symptoms are mild or when patient is at remission. Other factors which could lower the sensitivity of IFAT include variations in the substrate and subjective interpretation. In recent times, there have been some advances in standardization of the IFAT method which includes automation of the analytic procedure and recognition of the immunohistochemical pattern by way of computerized systems. However, these things are beyond scope for developing nations.

ELISA assay offers a suitable alternative as a preliminary investigation to exclude negative ANA sera. ELISA is technically simpler, and faster which could be useful in laboratories which screens large numbers of samples among which many could be ANA negative. The major advantage of ELISA is that it is not subjective in nature and is also more economical than the IFAT. However, the problem lies in samples with gray zone where each laboratory should identify a suitable cut-off ANA index which would segregate these samples from significantly positive ones. Retesting by the standard IFAT should be done for all low positive "gray zone" samples for confirmation of ANA positivity.

The ideal method should fulfill criteria of clinical sensitivity and high specificity, precision and accuracy, ease of execution, limited use of technology, quick availability, and contained costs [15]. At present, no method exists that fulfills all these requirements.

Thus, women without an autoimmune disorder history, but with complications during pregnancy, have a raised number of autoantibodies.
Further research in this topic that the occurrence of autoantibodies is transient particularly limited to pregnancy or postpartum or predictive of future immune related diseases are to be done in near future so that we prevent recurrent fetal wastage.

\section{REFERENCES}

1. Shankarakumar U, Pradhan VD, Patwardhan MM, Shankarakumar A, Ghosh K. Autoantibody profile and other immunological parameters in recurrent spontaneous abortion patients. Niger Med J 2011;52:3.

2. Pandey MK, Rani R, Agrawal S. An update in recurrent spontaneous abortion. Arch Gynecol Obstet 2005;272(2):95-108.

3. Internet Reference. Available from: http://www.srm-ejournal.com/ article.asp?AID=10215\&UIB. [Last accessed on 2012 Nov].

4. Kumar Y, Bhatia A, Minz RW. Antinuclear antibodies and their detection methods in diagnosis of connective tissue diseases. Diagn Pathol 2009;4:1.

5. Patton PE, Coulam CB, Bergstralh E. The prevalence of autoantibodies in pregnant and nonpregnant women. Am J Obstet Gynecol $1987 ; 157(6): 1345-50$.

6. Garcia-De La Torre I, Hernandez-Vazquez L, Angulo-Vazquez J, Romero-Ornelas A. Prevalence of antinuclear antibodies in patients with habitual abortion and in normal and toxemic pregnancies. Rheumatol Int 1984;4(2):87-9.

7. Nakatsuka M, Yoshida N, Hasegawa A, Nishikori K, Hirano Y, Katayama T, et al. Antinuclear antibody measurement as a screening test for sterile and infertile women with immunological abnormality. Nihon Sanka Fujinka Gakkai Zasshi 1993;45(5):431-6.

8. Farnam J, Lavastida MT, Grant JA, Reddi RC, Daniels JC. Antinuclear antibodies in the serum of normal pregnant women: A prospective study. J Allergy Clin Immunol 1984;73:596-9.

9. Xu L, Chang V, Murphy A, Rock JA, Damewood M, Schlaff W, et al. Antinuclear antibodies in sera of patients with recurrent pregnancy wastage. Am J Obstet Gynecol 1990;163:1493-7.

10. Satoh M, Chan EK, Ho LA, Rose KM, Parks CG, Cohn RD, et al. Prevalence and sociodemographic correlates of antinuclear antibodies in the United States. Arthritis Rheum 2012;64(7):2319-27.

11. Afman IE, Cronjé HS, Joubert G, Badenhorst PN, Schoon MG. Antinuclear antibody testing in obstetric patients. S Afr Med J 2003;93(12):932-7.

12. Bahar AM, Kwak JY, Beer AE, Kim JH, Nelson LA, Beaman KD, et al. Antibodies to phospholipids and nuclear antigens in non-pregnant women with unexplained spontaneous recurrent abortions. J Reprod Immunol 1993;24(3):213-22.

13. Kumagai S, Hayashi N. Immunofluorescence - Still the 'gold standard' in ANA testing? Scand J Clin Lab Invest Suppl 2001;235:77-83.

14. Divate S, Hardikar P, Bichile LS, Rajadhyaksha A. Clinical utility of screening for antinuclear antibodies by enzyme immunoassay - A preliminary study. J Assoc Physicians India 2004;52:290-3.

15. Tozzoli R, Bizzaro N, Tonutti E, Villalta D, Bassetti D, Manoni F, et al. Guidelines for the laboratory use of autoantibody tests in the diagnosis and monitoring of autoimmune rheumatic diseases. Am J Clin Pathol 2002;117(2):316-24 